\title{
Preparation and structure of polyether-block containing polymers
}

\author{
A. Boularès, C. Rodrigues, L. Rozès, M. Tessier and E. Maréchal \\ Laboratoire de Synthèse Macromoléculaire, Case 184, Université P.M. Curie \\ 4 Place Jussieu, 75252, Paris, Cédex, 05, France
}

\begin{abstract}
Block-copolymers were prepared by direct polycondensation of functional oligomers or by polycondensation of a functional oligomer with the precursors of another block. Three series of copolymers were prepared and characterized: poly(polyamide 12-block-copolyether)s, Polyisobutylene-block-polyoxyethylenegraft-polyoxyethylene and poly(semi-aromatic polyester-block-polyoxytetra methylene)s. The functional oligomers and the corresponding copoly-condensates were characterized by SEC, infra-red spectroscopy, mass spectrometry, ${ }_{1} \mathrm{H}$ and ${ }^{13} \mathrm{C}$ NMR (solution and solid state). Their thermal properties were analyzed and the extent of the segregation in poly(polyester semi-aromatic-blockpolyoxytetramethylene)s was studied through visco-elastic properties.
\end{abstract}

\section{INTRODUCTION}

A large part of the activity of our laboratory is devoted to block copolycondensates (ref. 1-16). We use three main methods:

(i) direct polycondensation of a,w-difunctional oligomers:

$\mathrm{X}$-[Oligomer 1]-X+Y-[Oligomer 2]-Y $Æ \sim X^{\prime}-[$ Block 1]-X'Y'-[Block 2]-Y'

(ii) polycondensation of an a,w-difunctional oligomer with the precursors of another block:

$\mathrm{X}$-[Oligomer 1]-X + A-A + B-B E $\sim \mathrm{X}^{\prime}-[$ Block 1]-X'Y'-[Block 2]-Y' with $Y^{\prime}-\left[\right.$ Block 2]-Y' is $A^{\prime} A^{\prime} B^{\prime} B^{\prime}-\left[A^{\prime} A^{\prime} B^{\prime} B^{\prime}\right]-A^{\prime} A^{\prime}$

(iii) oligomer-coupling reactions:

$\mathrm{X}$-[Oligo 1]-X + Y-[Oligo 2]-Y + C-C Æ $\sim \mathrm{X}^{\prime}-\left[\right.$ Block 1] $\mathrm{X}^{\prime} \mathrm{C}^{\prime} \mathrm{C}^{\prime} \mathrm{Y}^{\prime}[$ Block 2]-Y'

This lecture concerns the following copolymers:

Poly(polyamide 12-block-copolyether)s

Poly(polyisobutylene-block-polyoxyethylene-graft-polyoxyethylene)s

Poly(semi-aromatic polyester-block polyoxytetramethylene)s

\section{SYNTHESES OF THE BLOCK-COPOLYMERS}

\section{Poly(polyamide-block-copolyether)s}

They were prepared according to the following reaction scheme (general method I):

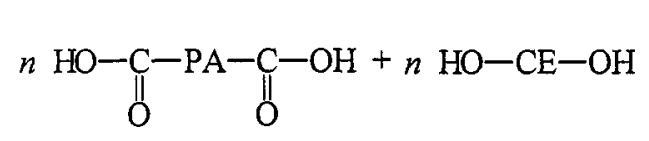

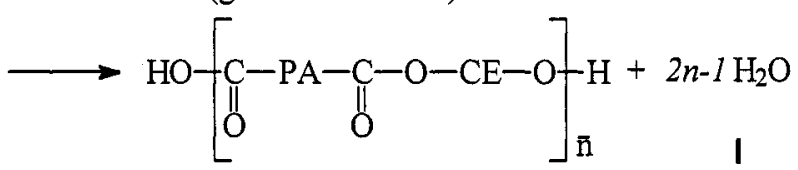

where $\mathrm{CE}$ is the copolyether-block

\section{Copolyethers}

We used Synperonic ${ }^{\circledR}$ (ICI) and Pluronic ${ }^{\circledR}$ (BASF). In principle, they are triblock-copolymers (POE-POPPOE) but in fact they are mixtures of triblock and biblock copolymers and polyoxypropylene; however all of them are difunctional. Their $\overline{\mathrm{Mn}}$ (Table 1) was obtained by SEC, MS, and ${ }^{1} \mathrm{H}$ NMR and the values obtained by these different techniques are in good agreement. Their composition and structure were essentially determined by ${ }^{1} \mathrm{H}$ NMR and ${ }^{13} \mathrm{C}$ NMR. 
TABLE 1. Characteristics of the copolyethers. [OE] and [OP] are the concentrations of oxyethylene and oxypropylene units; pri-OH and sec-OH are the concentrations of the primary and secondary end hydroxy-groups of the oligomers.

\begin{tabular}{|c|c|c|c|c|}
\hline Oligomers & $\overline{\mathrm{Mn}}{ }^{1} \mathrm{H}$ NMR & $\%[-\mathrm{OE}] /[\mathrm{OP}]$ & $\%$-pri-OH & $\%$-sec-OH \\
\hline Synperonic L-35 & 1920 & 1.26 & 90 & 10 \\
\hline Synperonic L-44 & 2205 & 1.09 & 85 & 15 \\
\hline Synperonic L-43 & 1840 & 0.77 & 80 & 20 \\
\hline Pluronic 4300 & 1925 & 0.65 & 80 & 20 \\
\hline Synperonic L-42 & 1570 & 0.26 & 75 & 25 \\
\hline Synperonic L-61 & 1950 & 0.23 & 60 & 40 \\
\hline Synperonic L-31 & 1090 & 0.25 & 50 & 50 \\
\hline Pluronic 6100 & 1740 & 0.14 & 45 & 55 \\
\hline Pluronic 3100 & 1095 & 0.16 & 35 & 65 \\
\hline
\end{tabular}

\section{Polv(semi-aromatic polyester-block-polyoxytetramethylene)s}

They were prepared according to the following reactionnal scheme (general method II):

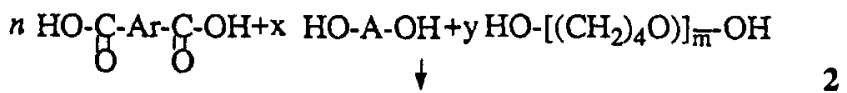

$$
\begin{aligned}
& \text { m[C }
\end{aligned}
$$

Six semi-aromatic copolymers were studied; in this lecture only the results relative to three of them are reported; they correspond to the scheme 3 .

When $\mathrm{A}$ is $\left(\mathrm{CH}_{2}\right)_{6}$ Ar can be:

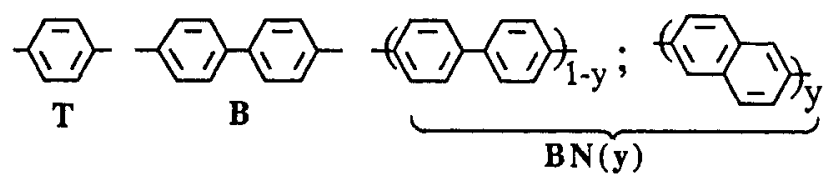

$\mathrm{y}$ is the contribution of $\mathrm{N}$ in $\mathrm{Ar}(\mathrm{mol} \%)$

3

The block-polyester can be also:

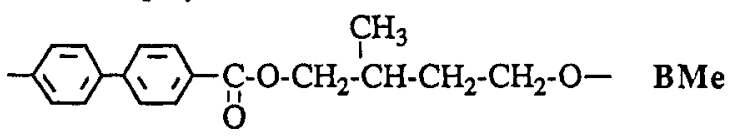

\section{Polvisobutylene-block-polyoxyethylene-graft-polyoxyethylene}

They were prepared according to the following reactionnal scheme (general method I):

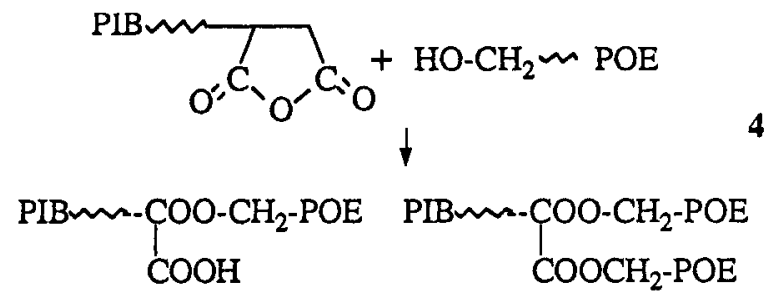


a-chloro oligoisobutylenes were prepared according to Nguyen and Kennedy (ref. 17) and improved by Rodrigues (ref. 18); they were dechlorinated, giving a-isopropenyl oligoisobutylenes, then reacted with maleic anhydride; these reactions were particularly studied by Tessier (ref. 19,20).

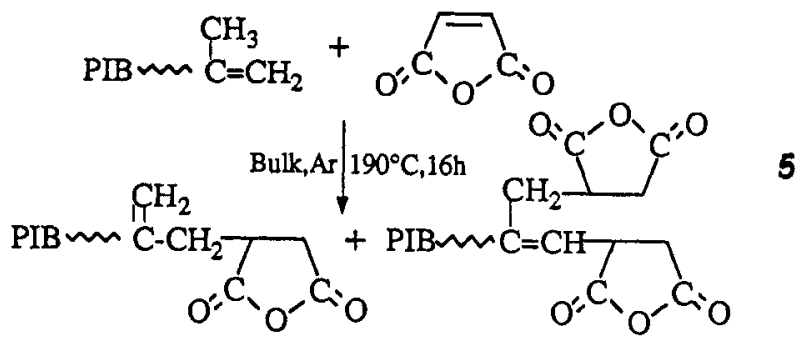

\section{CHARACTERIZATION OF THE BLOCK COPOLYMERS}

\section{Poly(polyamide-block-copolvether)s}

The block-copolymer prepared from L-35 exhibits the following characteristics: $[\mathrm{h}]=1.3 \mathrm{dL} . \mathrm{g}^{-1}$ and $\overline{\mathrm{Mn}}$ is above 20000 . The functionnal end group signals are no longer observed in the corresponding ${ }^{1} \mathrm{H} \mathrm{NMR}$ spectrum and those of the methylene preceding $(2.35 \mathrm{ppm})$ and following $(4.25 \mathrm{ppm})$ the ester group confirm that the polycondensation took place. Solid state NMR spectroscopy provides interesting information on several copolymers.

The crystalline domains of the precursory oligoamide and of the polyamide-blocks are $\mathrm{g}$ monoclinic structures which is confirmed by X-ray diffractometry. The polyether-block of a poly[polyamide-blockpolyoxytetramethylene] is amorphous when its $\mathrm{Mn}$ is 1000 and partially crystallized when $\mathrm{Mn}$ is 2000 .

The polyether-block of a poly[polyamide-block-polyoxyethylene] contains a crystalline phase and an amorphous one. On the other hand the polyether blocks of poly[polyamide-block-polyoxypropylene] and of poly[polyamide-block-copolyether] are amorphous. Their thermal properties are reported in table 2.

TABLE 2. Thermal properties of poly[polyamide-block- polyether]s. $\operatorname{Tg}, \operatorname{Tm}, \operatorname{Tr}\left({ }^{\circ} \mathrm{C}\right)$; $\nexists \mathrm{H}_{\mathrm{m}}, \circledast \mathrm{H}_{\mathrm{r}}\left(\mathrm{J} . \mathrm{g}-{ }^{1}\right)$ are respectively glass transition, melting and crystallisation

\begin{tabular}{|c|c|c|c|c|c|c|c|}
\hline \multirow[t]{2}{*}{ Polymer $\overline{\mathrm{Mn}}$} & \multicolumn{4}{|c|}{ Heating } & & \multicolumn{2}{|c|}{ Cooling } \\
\hline & TgPE & $\operatorname{TmPE}$ & $Æ \mathrm{H}_{\mathrm{mPE}}$ & TmPA & $\nexists \mathrm{EH}$ & $\mathrm{T}_{\mathrm{rPA}}$ & $Æ H_{\mathrm{rPA}}$ \\
\hline PA12DC (2100) & - & - & & 166 & 75 & 138 & 59 \\
\hline POE (1015) & - & 47 & 136 & & & & \\
\hline POP (928) & -52 & - & - & & & & \\
\hline PTOM (1075) & -83 & 27 & 107 & & & & \\
\hline PA-POE & -40 & 7 & 5 & 166 & 37 & 132 & 39 \\
\hline PA-POP & -47 & - & - & 161 & 38 & 133 & 37 \\
\hline PA-POTM & -50 & 11 & 3 & 162 & 33 & 131 & 35 \\
\hline L31 & -55 & - & - & & & & \\
\hline 235 & -52 & 28 & 15 & & & & \\
\hline PA-L31 & -44 & & & 164 & 36 & 135 & 36 \\
\hline PA-L35 & -44 & & & 168 & 30 & 135 & 31 \\
\hline
\end{tabular}

TmPA, $Æ H m P A, T r P A$ and $Æ H r P A$ little depend on polyether nature and $\overline{\mathrm{Mn}}$. The polyether block $\mathrm{Tg}$ is above that of the precursor. 


\section{$\underline{\text { Polv(semi-aromatic polvester-block-polvoxytetramethylene)s }}$}

Their structure is given by formula 6 :

$$
\begin{aligned}
& \sim[-\mathrm{C}-\mathrm{Ar}-\mathrm{C}-\mathrm{O}-\mathrm{A}-\mathrm{O}]-\mathrm{C}-\mathrm{C}-\mathrm{Ar}-\mathrm{C}-\left[-\mathrm{O}\left(\mathrm{CH}_{2}\right)_{4}-\frac{-\mathrm{O}^{\circ}}{\mathrm{m}} \mathrm{O}\right. \\
& R \text { is }\left[-\mathrm{C}_{\mathrm{O}}-\mathrm{Ar}-\mathrm{C}-\mathrm{O}-\mathrm{O}-\mathrm{A}-\mathrm{O}\right]_{\overline{\mathrm{x}}} \text { and } \mathrm{F} \text { is }\left[-\mathrm{O}\left(\mathrm{CH}_{2}\right)_{4}^{-]} \overline{\mathrm{m}}\right.
\end{aligned}
$$

Ar and A structures are given in scheme 3.The $\overline{\mathrm{Mn}}$ of $\mathbf{R}$ blocks $\left({ }^{1} \mathrm{H}\right.$ NMR) is given in table 3. The $\overline{\mathrm{Mn}}$ of $\mathbf{F}$ is 2100 and their thermal and mesomorphic properties are reported in table 4

TABLE 3. $\overline{\mathrm{Mn}}$ of the blocks in the copolycondensates. Theoretical values are given in brackets.w is the weight percentage of $\mathbf{F}$ in $\mathbf{R}-\mathbf{F}$

\begin{tabular}{|c|ccc|}
\hline Copolymer & $\mathrm{x}$ & $\overline{\mathrm{Mn}}$ of $\mathbf{R}$ & $\mathrm{F}(\mathrm{w} \%)$ \\
\hline T-F & $31(28)$ & $7650(6860)$ & $23(25)$ \\
B-F ( & $20(22)$ & $6440(7092)$ & $27(25)$ \\
BN(26)-F & $23(22)$ & $7365(7070)$ & $24(25)$ \\
BMe-F & $15(15)$ & $4670(4730)$ & $34(33)$ \\
\hline
\end{tabular}

TABLE 4. Thermal and mesomorphic properties of the copolymers. Ti is isotroposition temperature and $\mathbb{E T}$ is the temperature mesomorphic domain.

\begin{tabular}{|l|lllll|l|}
\hline Polymer & Tg,F & Tm,F & Tm,R & Ti & ÆT & Mesophase \\
\hline F & -83 & 35 & - & - & - & - \\
\hline T & - & - & 147 & - & - & - \\
T-F(34) & -74 & 17 & 144 & - & - & - \\
\hline B & - & - & 214 & 241 & 27 & Smectic A \\
B-F(27) & -76 & 28 & 223 & 231 & 8 & Smectic A \\
B-F(50) & -78 & 25 & 224 & 233 & 9 & Smectic A \\
\hline BN(25) & - & - & 192 & 227 & 35 & Smectic A \\
BN(26)-F(24) & -77 & 29 & 197 & 209 & 12 & Smectic A \\
\hline BMe & - & - & 214 & 232 & 18 & Nematic \\
BMe-F(26) & -81 & 26 & 215 & 231 & 16 & Nematic \\
\hline
\end{tabular}

We compared the segregation extent when $\mathrm{Ar}$ is benzenic ring (the copolycondensate is not mesomorphic) and when the copolycondensate exhibits mesomorphic properties B,BN,BMe); in this purpose their viscoelastic properties were studied (table 5).

TABLE 5. Temperature TE"max $\left({ }^{\circ} \mathrm{C} ; 1 \mathrm{~Hz} ; 10^{\circ} \mathrm{C} \mathrm{min}-1\right)$.

\begin{tabular}{|l|l|l|l|l|l|}
\hline Copolymer & TE"max & Copolymer & TE"max & Copolymer & TE"max \\
\hline T-F(23) & -4 & T-F(34) & -37 & T-F-(43) & -63 \\
\hline B-F(27) & -51 & B-F(33) & -53 & B-F(50) & -46 \\
\hline BN(26)-F(24) & $-46 /-20$ & BN(30)-F(34 & $-46 /-20$ & BN(28)-F(49) & $-47 /-20$ \\
\hline BMe-F(20) & -49 & BMe-F(26) & -55 & BMe-F(34) & -56 \\
\hline
\end{tabular}

The rheological properties in the melt were studied. With $\mathbf{T}$ the solid/liquid transition is characteristic of an isotropic material: $G^{\prime \prime}$ is always far above $G^{\prime}$ and its value is proportional to the pulsation (w) whatever $T$. On the other hand with $\mathbf{B}$ or $\mathbf{B N ~ G '}$ is above $\mathrm{G}^{\prime \prime}$ when $\mathrm{T}$ is below Tm showing it is an elastic solid material. 
When $\mathrm{Tm}<\mathrm{T}<\mathrm{Ti}, \mathrm{G}^{\prime}$ and $\mathrm{G}^{\prime \prime}$ are very closed and rapidly decrease with $\mathrm{T}$ increasing which is characteristic of a smectic phase; in this domain $G^{\prime \prime}$ is roughly proportional to $w^{0.5}$. When $T>T i$, the corresponding isotropic liquid is characterized by $\mathrm{G}^{\prime \prime}>\mathrm{G}^{\prime}$. The nematic state of B-Me-copolymers is characterized by a weak decrease of $\mathrm{G}^{\prime}$ and $\mathrm{G}^{\prime \prime}$ when $T$ increases.

\section{Polyisobutylene-block-polvoxyethylene-graft-polyoxyethylene}

The reaction product of anhydride-oligoisobutylenes with a-hydroxy-polyoxyethylene (7) was characterized by infra-red spectroscopy, mass spectrometry and SEC.

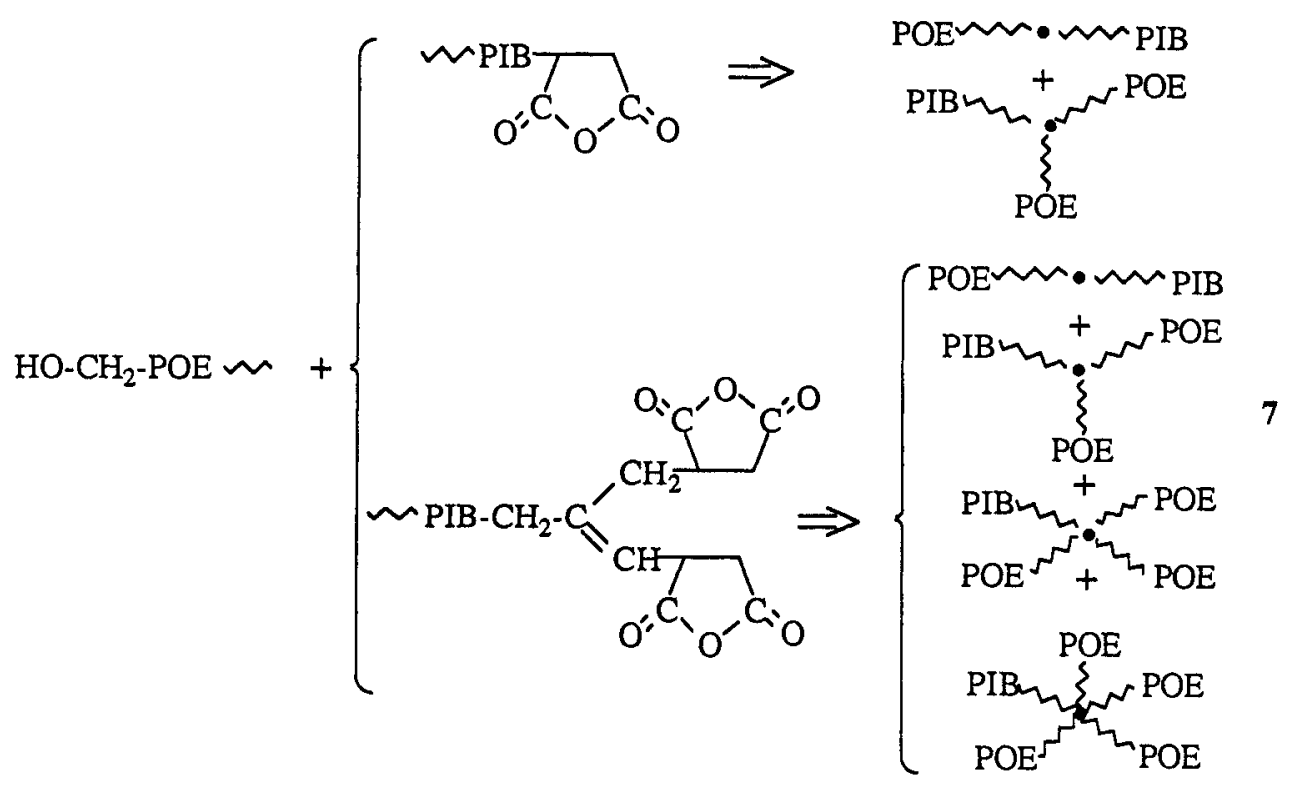

characteristics do not depend on the structure of the oligoisobutylene. When the $\overline{\mathrm{Mn}}$ of POE is $815 \mathrm{Tg}$ is $64^{\circ} \mathrm{C}$, crystallisation temperature is $-45.5^{\circ} \mathrm{C}$ and $\mathrm{Tm}$ is $24.5^{\circ} \mathrm{C}$; when it is $2015 \mathrm{Tg}$ is $-45^{\circ} \mathrm{C}$, $\mathrm{Tm}$ is $49^{\circ} \mathrm{C}$. Some of their amphiphilic properties were determined and particularly cloud-point and surface-tension. Their water solubility is high due to the fact that the hydrophobic block has a low molar mass; they have a classical behaviour of non-ionic surfactant.

\section{REFERENCES}

1. G. Deleens, P. Foy and E. Maréchal, Europ. Polym. J. 13, 337,343,353 (1977).

2. Ch.Leriche, Ch. Michaud and E. Maréchal, Bull. Soc. Chim. (Chim. Mol.), 717 (1977)

3. A. Fradet and E. Maréchal, Europ. Polym. J. 14, 749,755,761 (1978).

4. P.J. Madec and E. Maréchal, J. Pol. Sci. 16, 3157,3165,(1978).

5. M. Tessier and E. Maréchal, Europ. Polym. J. 20, 281 (1983).

6. A.Pourjavadi, P.J. Madec and E. Maréchal, Europ. Polym. J. 20,305,311 (1984).

7. D.Gagnebien, P.J. Madec and E. Maréchal, Europ. Polym. J. 21,273,289,301 (1985).

8. G. Torres, P.J. Madec and E. Maréchal, Makromol. Chem. 190, 203,2789,(1989).

9. M. Tessier, E. Maréchal, J. Pol. Sci. Polym. Chem. Ed. 27, 539 (1989).

10. P.J. Madec, R.Pérès,E. Maréchal, Makromol. Chem.,Macromol. Symp. 47,35 (1991).

11. T. Nykolyszak, A. Fradet and E. Maréchal, Makromol. Chem. 193, 2231 (1992).

12. Th. Galcera, A. Fradet and E. Maréchal, Makromol. Chem., Macromol. Symp. 64, 33 (1992).

13. P. Thuillier, M. Tessier and E. Maréchal, Makromol. Chem., Macromol. Symp. 70/71, 37 (1993); Molecular Crystals and Liquid Crystals Science and Technology. Section A 254, 1 (1994).

14. Th. Galcera, A. Fradet and E. Maréchal, Eur. Polym.J. 31, 733 (1995).

15. A.Boularès, M. Tessier and E. Maréchal, to be published. 
16. E. Borgès, P.J. Madec and E. Maréchal,Polym. Bull. 34, 523 (1995).

17. H.A. Nguyen and J.P. Kennedy, Polym. Bull., 9,507 (1983).

18. C. Rodrigue, M. Tessier and E. Maréchal, to be published.

19. M. Tessier and E. Maréchal, Eur. Polym.J. 20, 269 (1984) and 26, 499 (1990).

20. M. Tessier and E. Maréchal, Polym. Bull. 10, 152 and (1983). 